\title{
Properties of the Broad-Range Nematic Phase of a Laterally Linked H- Shaped Liquid Crystal Dimer
}

Young-Ki Kim, ${ }^{a}$ Randall Breckon, ${ }^{b}$ Saonti Chakraborty, ${ }^{c}$ Min Gao, ${ }^{a}$ Samuel N. Sprunt, ${ }^{c}$ James T. Gleeson, ${ }^{c}$ Robert J. Twieg, ${ }^{b}$ Antal Jákli, ${ }^{a}$ and Oleg D. Lavrentovich ${ }^{a}$

${ }^{a}$ Liquid Crystal Institute and Chemical Physics Interdisciplinary Program, Kent State University, Kent, $\mathrm{OH} 44242$, USA

${ }^{b}$ Department of Chemistry \& Biochemistry, Kent State University, Kent, OH 44242 , USA

${ }^{c}$ Department of Physics, Kent State University, Kent, OH 44242, USA.

* Corresponding author. E-Mail : olavrent@kent.edu

\begin{abstract}
In search for novel nematic materials, a laterally linked H-shaped liquid crystal dimer have been synthesized and characterized. The distinct feature of the material is a very broad temperature range (about $50{ }^{\circ} \mathrm{C}$ ) of the nematic phase, which is in contrast with other reported H-dimers that show predominantly smectic phases. The material exhibits interesting textural features at the scale of nanometers (presence of smectic clusters) and at the macroscopic scales. Namely, at a certain temperature, the flat samples of the material show occurrence of domain walls. These domain walls are caused by the surface anchoring transition and separate regions with differently tilted director. Both above and below this transition temperature the material represents a uniaxial nematic, as confirmed by the studies of defects in flat samples and samples with colloidal inclusions, freely suspended drops, X-ray diffraction and transmission electron microscopy.
\end{abstract}

Keywords: biaxial nematic; H-dimer; anchoring transition; domain wall; smectic nanocluster 


\section{Introduction}

Liquid crystals (LCs) with their numerous thermodynamically stable phases present a dramatic illustration of how a small alteration of the molecular structure can lead to profound changes in the long-range order. The simplest uniaxial nematic phase that enabled the LCD industry, is typically formed by rod-like molecules with a straight central rigid core and two aliphatic chains. The rods prefer to align parallel to each other, along a single axis, called the director $\hat{\mathbf{n}}$, setting anisotropic character of all physical properties of the material.[1] An intriguing example is represented by molecules with two rod-like rigid elements connected by a flexible aliphatic tail with an odd number of methylene groups [2-10]: these dimers form the so-called twist-bent nematic phase [11-14] with nanoscale periodic modulation of the director.[15, 16] As shown by transmission electron microscopy (TEM), the underlying nanoscale periodic motif represents an oblique helicoid.[16] The structure is thus intermediate between the normal uniaxial nematic $\left(\mathrm{N}_{\mathrm{u}}\right)$ and the chiral nematic.

The fourth nematic is the so-called biaxial nematic $\left(\mathrm{N}_{\mathrm{b}}\right)$, in which the uniform alignment of, say, the longest axes of the molecules, is accompanied by uniform orientation of the short axes. $\mathrm{N}_{\mathrm{b}}$ was first identified by $\mathrm{Yu}$ and Saupe in a lyotropic mixture of potassium laurate / 1-decanol / water system.[17] Although the biaxial order has been observed by other researchers in this and other lyotropic nematics,[18-27] the issue remains controversial, as the studies by Berejnov et al. $[28,29]$ suggest that the biaxial order is only transient.

Existence of a thermotropic $\mathrm{N}_{\mathrm{b}}$ is even less clear. The most recent search focused on the so-called bent-core mesogens. In the bent-core materials with oxadiazole units, $\mathrm{N}_{\mathrm{b}}$ was identified in the studies of X-ray diffraction (XRD),[30, 31] 
NMR \& conoscopy,[32] electro-optical switching,[33-36] and topological defects.[37] However, reexamination of how materials behave in the external fields and in confined geometries with topological defects, lead to a conclusion that two oxadiazole compounds, abbreviated $\mathrm{C} 7$ and $\mathrm{C} 12$, are uniaxial nematics that mimic the behavior of $\mathrm{N}_{\mathrm{b}}$ because of effects such as surface anchoring transitions.[38, 39]

The $\mathrm{N}_{\mathrm{b}}$ phase was also claimed in the azo-substituted bent-core nematic A131, following XRD and DSC,[40] NMR,[41] conoscopy,[42, 43] and Raman scattering experiments.[44]. More recent NMR studies resulted in a conclusion that it is necessary to test the material for possible conformational changes [45] and that a transition within the nematic range of A131, identified as one from the uniaxial to the biaxial phase, can be associated with a slowing down of the molecular rotations around the long molecular axis.[46] Two other similar azo compounds have also been claimed to feature the $\mathrm{N}_{\mathrm{b}}$ phase on the basis of XRD [40, 47] and conoscopy [43] studies. However, explorations of electro- and magneto-optics, surface alignment and defects showed that the nematic order in A131 is uniaxial.[39, 48, 49]

One of the reasons for the controversy is that uniaxial nematic phase can mimic the features of the $\mathrm{N}_{\mathrm{b}}$ phase in a variety of forms. Very often this mimicking behavior is rooted in the complexity of surface alignment of molecules with nontrivial shapes such as bent-core [38, 49] and tetrapodes mesogens.[50] An interesting example of mimicking behavior is demonstrated by a mesogen with four lateral flexible chains.[51] The biaxial-like features occur as a result of thermal expansion which triggers flows; the latter cause a biaxial tilt of the uniaxial director that can persist for hours because of high viscosity of the material.[51, 52]

The examples above are by no means an indication that all of the potentially $\mathrm{N}_{\mathrm{b}}$ 
are in fact uniaxial. As of today, the claimed existence of the $\mathrm{N}_{b}$ phase has not been challenged for bent-core mesogens with oxadiazole $[31,53,54]$ and azo-groups, $[40,43$, 47] for strongly asymmetric units, $[55,56]$ and for the shape-persistent derivatives of benzodithiophene $[57,58]$ and fluorenone. $[43,59-61]$ The state of the art of biaxiality in bent-core nematics and in other shape LCs have been reviewer recently.[62, 63] Other molecular geometries, such as mesogens with four flexible chains, $[64,65]$ tetrapode derivatives [66-71] different from the one explored in Ref. [50] also show $\mathrm{N}_{\mathrm{b}}$ features that have not been disputed so far. Finally, there is an interesting but underexplored class of compounds with cyclic (ring-like) mesogens synthesized by Percec [72-74] with the $\mathrm{N}_{b}$ features in phase behavior $[72,73]$ and in structure of wall defects.[74]

It is of interest to note that optical biaxiality in the uniaxial nematic can be induced by the external electric or magnetic field, including the case of bent-core mesogens [75-80]. However, the field-induced effects involve multiple mechanisms, including uniaxial and biaxial modifications of the order parameter and also modification of the director fluctuations, which are often difficult to separate from each other.[81, 82] In this work, we deal with the situations in which the electric field suppresses potentially biaxial features (such as domain walls, see below for more details) and thus does not induce the $\mathrm{N}_{\mathrm{b}}$ phase.

Obviously, the different symmetry of the long-range nematic order implies different types of physical properties and ensuing applications. Uniaxial nematics are widely exploited in LCDs, chiral nematics are used in light-reflecting devices, while twist-bend nematics show interesting polar electro-optic effects $[4,10]$ and distinct electric field-induced reorientation caused by dielectric anisotropy.[16] The biaxial 
nematics are expected to speed up the electrooptic response as compared to their uniaxial counterparts.[83] The short review presented above makes it clear, however, that the identification of the true connection between the molecular structure and phase symmetry is often a difficult task and requires one to use multiple experimental techniques, especially those that do not depend on the integrated response of the sample but instead probe the local order, as in the case of topological defects.

In this work, in search for novel nematic materials, we have synthesized (Synthetic processes are available in Electronic Supplementary Information) and explored the LC abbreviated RB01189, formed by mesogenic dimers in the shape of letter ' $\mathrm{H}$ ', the so-called H-dimers, Figure 1a, b. Typically, H-dimers form smectic phases.[84-88] The distinct feature of the material explored in this work is a very broad temperature range of the nematic phase, about 50 degrees. The material shows intriguing textural features, both at the scale of microns and at the scale on nanometers. In particular, optical textures reveal peculiar defects that appear at a certain temperature. A detailed study of the optical features of these defects through regular polarizing microscopy and quantitative mapping of optical retardance demonstrates that they represent domain walls that appear as a result of surface anchoring transition. The walls separate regions with different tilt of the director $\hat{\mathbf{n}}$. Both above and below the temperature at which the domain walls appear, the H-dimer material retains its uniaxial nematic order. At the scale of nanometers, the material show traces of smectic clustering. 


\section{Results and discussion}

\subsection{Phase diagram, alignment, and birefringence}

To establish the phase diagram and to explore the textures of RB01189, we used flat glass cells with transparent indium tin oxide electrodes. The cell thickness $d$ was set by spacers. All the experiments were performed above the crystallization temperature to prevent a possible memory effect.[38] The temperature was controlled by a hot stage LTS350 with a controller TMS94 (both Linkam Instruments) with $0.01^{\circ} \mathrm{C}$ accuracy. A typical rate of temperature change was $\pm 0.1^{\circ} \mathrm{C} / \mathrm{min}$ to minimize the effects of thermal expansion.[51, 52] The phase diagram of RB01189 determined by polarizing microscopy upon cooling is:

$$
\mathrm{Cr}<56^{\circ} \mathrm{C}<\mathrm{N}<108^{\circ} \mathrm{C}<\mathrm{I}
$$

where $\mathrm{Cr}, \mathrm{N}$, and I indicate the crystal, nematic, and isotropic phases, respectively. The $\mathrm{N}$-I transition temperature $T_{\mathrm{NI}}$ varies within $1-3^{\circ} \mathrm{C}$ depending on the cell thickness $d$ and alignment layer; $T_{\mathrm{NI}}$ is constant within the entire area of the same cell. The material shows a $2^{\circ} \mathrm{C}$ biphasic region with coexisting $\mathrm{N}$ and I phases.

We used two polyimides as the aligning layers (AL), namely, PI2555 (AL1, HD Microsystems) and SE5661 (AL2, Nissan Chemical Industries). For the classical uniaxial LCs such as 5CB and E7, AL1 provides a tangential (in-plane) alignment, while AL2 yields a perpendicular (homeotropic) alignment of the director $\hat{\mathbf{n}}$. In the case of RB01189, the situation is more complex. Judged by the Schlieren textures with isolated centers showing two and four extinction brushes (disclinations and point defects, respectively), AL1 provides a strictly tangential anchoring in the entire temperature range of the $\mathrm{N}$ phase, there is no tilt.[1, 89] AL2 shows either a tangential 
or tilted alignment of $\hat{\mathbf{n}}$, depending on temperature, as discussed in the next section. We used unidirectionally rubbed cells of thickness $d=1.4 \mu \mathrm{m}$ with AL1 to measure the birefringence $\Delta n$ as a function of the effective temperature $t=T-T_{\mathrm{NI}}$ in the $\mathrm{N}$ phase, Figure 1c.

\subsection{Anchoring transitions and domain walls.}

AL2 cells show an interesting sequence of textures that depend both on temperature and the cell thickness $d$. At high temperatures, the cell with $d=6 \mu \mathrm{m}$ shows Schlieren textures typical of tangentially anchored cells, Figure $2 a$, with defect centers at which two or four extinction bands converge. Below a certain temperature $t_{1}$, a network of domain walls (DWs) with interference colors different from the background emerges in the texture, Figure $2 \mathrm{~b}$. Their appearance is very similar to the so-called "secondary disclinations" identified as the disclinations that signal presence of $\mathrm{N}_{\mathrm{b}}$.[37] However, in our case, these defects represent DWs of the uniaxial nematic, associated with the tilted surface anchoring at the substrates of the $\mathrm{N}_{\mathrm{u}}$ cell, as analyzed below.

As the temperature decreases, the contrast of the DWs first enhances and then decreases, Figure 2c-f. To quantify the change in the contrast, we used PolScope technique that maps the optical retardance $\Gamma$ of the cell as a function of the in-plane $(x, y)$ coordinates.[90-92] The maximum value of the measured retardance allowed by PolScope is limited by $273 \mathrm{~nm}$, thus we used a thin cell with $d=1.4 \mu \mathrm{m}$, Figure 3. In the thin cell, the DWs form immediately after the isotropic-nematic transition, i.e., $t_{1}=0^{\circ} \mathrm{C}$. The optical retardance at the center of the DW is higher than in the background, Figure 3a-d. As the temperature decreases, the background retardance 
increases and eventually, the retardance of the surrounding regions matches the retardance of the DW. Variation of $\Gamma$ along a line that crosses one of the DWs (dotted line in Figure 3a-d) is presented in Figure 3e for different temperatures. The maximum value of $\Gamma\left(\Gamma_{\max }\right)$ is reached at the center of the DW (labeled by a symbol * in Figure 3a-d). For an extended temperature range, $\Gamma_{\max }$ matches the maximum possible value of retardance $d \Delta n$ that is reached when the director is strictly planar, Figure $3 \mathrm{f}$. The fact that $\Gamma_{\max }=d \Delta n$ means that the defect represents a DW [89] with a tangentially aligned central part, separating regions with tilted director and thus smaller retardance. In Schlieren textures of samples with tilted alignment, the DWs are stabilized by the defect centers with two extinction brushes, since these centers correspond to vertical disclinations around which the director rotates by $180^{\circ}$. In contrast, the cores with four extinction brushes that correspond to the point defects-boojums [89] can accommodate the titled alignment without creating DWs. In Figures 2 d,e, one can clearly see that the centers with two brushes are connected by DWs but the centers with four brushes remain DW-free.

Figure 4 shows the detailed director pattern and the retardance map around DWs in an AL2 cell of $d=1.1 \mu \mathrm{m}$ at $t=-1.4^{\circ} \mathrm{C}$. The center of the DW is easily identifiable as the region with the highest retardance. One can distinguish two limiting cases, depending on the predominant deformation of the director $\hat{\mathbf{n}}$ across the wall: a splaybend DW, Figure 4b, and a twist DW, Figure 4c. Note also that the DWs might also occur as closed loops, some of which are visible in Figure 2b,c.

To prove further that the textural defects in AL2 cells are DWs caused by the tilted surface alignment, we explored the electrooptic response of the texture. RB01189 has a negative dielectric anisotropy, $\Delta \varepsilon<0$. Applying an electric field across the cell, one 
should reorient the director perpendicular to the field and thus establish a tangential orientation everywhere with no DWs. Figure 5 shows that this is indeed the case. By applying a vertical AC electric field (sinusoidal wave, frequency $f=1 \mathrm{Khz}$ ) to the AL2 cell with $d=1.4 \mu \mathrm{m}$, one increases the retardance in the regions outside the DWs, which implies that the director becomes more parallel to the bounding plates. The maximum retardance measured at $5 \mathrm{~V}_{\mathrm{PP}}$ is $93 \mathrm{~nm}$. For $d=1.4 \mu \mathrm{m}$, it corresponds to the effective birefringence 0.066 , which is close to the birefringence measured 0.064 in the planar cell at the same temperature, $t=-1.5^{\circ} \mathrm{C}$. At sufficiently high voltage $\left(>4 \mathrm{~V}_{\mathrm{PP}}\right)$, the DWs disappear and the retardance does not show any significant variation in the plane of the sample (except at the cores of disclinations and boojums at which the retardance is smaller).

We conclude that the observed DWs are caused by the tilted alignment in AL2 cells. In thick samples, the orientation is tangential above $t_{1}$ and tilted below $t_{1}$. As the director realigns from the tangential to tilted, the DWs form in order to separate regions with the different direction of tilt. The fact that these DWs are not observed in AL1 cells (in which the director remains parallel to the bounding plates in the entire range of the $\mathrm{N}$ phase) and the fact that the temperatures of appearance of DWs in thin and thick AL2 cells are different from each other, further supports the conclusion that the DW are not associated with the $\mathrm{N}_{\mathrm{u}}-\mathrm{N}_{\mathrm{b}}$ transition. The next section confirms the $\mathrm{N}_{\mathrm{u}}$ type of ordering in the entire range of the RB01189 nematic phase, through the studies of defects in colloidal-LC composites. 


\subsection{Point defects in droplets and around colloidal spheres}

Topological defects are often used for phase identification of LCs, as these are uniquely defined by the order parameter type.[89] The straightforward approach [38, 49, 50, 9395] is to use colloidal settings in which the topological defects correspond to the equilibrium state of the LC. It can be a spherical droplet of a LC that must feature a certain number of topological defects because of its shape,[93] or it can be a colloidal sphere immersed in the LC bulk that causes similar defects around itself.[96] We explored both situations for RB01189, Figure 6.

RB01189 droplets were dispersed in glycerol (Sigma-Aldrich). They show a bipolar texture with two isolated boojums in the entire N range, Figure 6a, d-g. Such a texture is a classic example of a uniaxial nematic confined in the sphere with tangential surface anchoring.[93, 97] It is very different from the biaxial nematic droplet, in which the boojums at the poles must be connected by a disclination line as shown in Figure $6 \mathrm{~b}$, or combine two boojums into one, Figure $6 \mathrm{c}$.

We have also explored the surface point defects-boojums around spherical colloids that set a tangential orientation of the surrounding director in RB01189. The borosilicate glass spheres were dispersed in uniformly aligned planar AL1 cells of $d=20 \mu \mathrm{m}$. Each spheres produces only a pair of boojums at its poles and no other defects, Figure $6 \mathrm{j}, \mathrm{k}$, which is again consistent with the uniaxial (Figure 6h) but not with the biaxial charater (Figure 6i) of order, as discussed in Refs. [38, 49]. The features of topological defects in colloid-LC samples confirm that RB01189 is a uniaxial nematic. 


\subsection{Smectic nanoclusters in the nematic phase : small angle $X$-ray scattering study}

\section{\& TEM observation.}

The small angle X-ray scattering (SAXS) patterns with four peaks are similar to those for the uniaxial nematic phase of bent-core LCs containing smectic C clusters, i. e., show nanoinclusions with layered structure in which the molecules are tilted with respect to the normal to the layers. $[98,99]$ The distance of the maxima of the four spots from the origin yields the wavenumber $q=0.285 \AA^{-1}$ corresponding to a layer periodicity of $p=2.2 \mathrm{~nm}$, which is considerably shorter than the approximate length $l \sim 3.7 \mathrm{~nm}$ of the fully extended aromatic legs of the dimers, indicating a large tilt angle $\theta$ that the aromatic legs make with the smectic layers' normal. The temperature dependence of the tilt angle $\theta$, determined from the angle between the magnetic field and the maxima of the spots, is shown in Figure 7a. The tilt angle is indeed large, over $50^{\circ}$, and barely depends on temperature below the biphasic range (more than $2^{\circ} \mathrm{C}$ away from the isotropic phase). The full width at half maxima of the $I(q)$ curves yields $\Delta q \sim 0.13 \AA^{-1}$, which is also fairly constant in the entire nematic range. The correlation length $\xi$ of the smectic clusters is therefore $\xi=2 / \Delta q \sim 1.54 \mathrm{~nm}$, which corresponds to a typical cluster size of about $3.1 \mathrm{~nm}$ (somewhat increases toward lower temperatures). The short correlation length and the small cluster size imply that the smectic layers in the LC bulk are poorly correlated. The reason might be the possibility of interdigitated arrangements of the $\mathrm{H}$ dimers on both sides of a single smectic layer with a large tilt angle $\theta$. These interdigitated arrangements might involve multiple conformational states with different shifts of the molecules along the direction of aromatic legs and thus would weaken the smectic correlations. 
Direct Cryo-TEM (figure 7b) and Freeze-Fracture TEM (Figure 7c) observations were carried out following the sample preparation described in Ref. [16, 100] to check the physical presence of layered clusters. Most areas do not show periodic structures, which is consistent with the small size of the cybotatic groups. However, in some areas, we find regions with periodic modulations that extend in the direction perpendicular to the "layers" over a significant distance of about $100 \mathrm{~nm}$. The periodicity of the fringes is (3.4-3.8 nm) in both cryo-TEM, Fig.7b, and in freeze-fracture TEM, Fig.7c, which is close to the length of the aromatic leg of the dimer, but significantly larger than the smectic layer spacing deduced from SAXS experiments. The cryo-TEM data might imply that the very small thickness of the cryo-TEM specimen (typically less than 100 $\mathrm{nm}$ ) forces the molecules to be in the plane of the sample and reduces the tilt angle $\theta$. A similar effect of confinement-induced suppression of the molecular tilt has been observed in smectic phases formed by bent-core molecules.[101] The freeze-fracture TEM data might be explained by the tendency of fractures to be along the lowest density of molecules, which is the direction parallel to the longest extension of the molecules.

\section{Conclusions}

In this study, we synthesized an H-shaped LC dimer RB01189 with a broad-range nematic phase and explored its physical properties. The material is a uniaxial nematic with embedded smectic nanoclusters that exist in the entire range of the nematic phase. The smectic nanoclusters are evident not only in the X-ray scattering experiments, but are also directly visible in two different modes of TEM observations.

Despite the complex molecular structure, the rubbed polyimide layers of PI2555 can align RB01189 uniformly. At some aligning substrates, such as SE5661, the H-dimer 
material shows surface anchoring transitions, with the director changing its surface orientation from tangential to tilted. The transition is accompanied by appearance of the domain walls, across which the uniaxial director changes its orientation from tilted to planar and back to tilted, to accommodate two neighbouring domains with a different direction of tilt. The walls are similar in appearance to the secondary disclinations described recently as a feature of the biaxial order but in the H-material under study, they have a very different nature associated with the variation of surface orientation of the uniaxial director. Finally, the broad temperature range of the nematic phase makes the H-dimers suitable candidates for the search of the remaining missing nematic, the so-called splay-bend phase. $[11,12,14]$ It is expected that $\mathrm{H}$-dimers with an odd number of methylene groups in the aliphatic bridge might form splayed configurations that would facilitate a formation of the splay-bend nematic. These studies are in progress.

\section{Experimental section}

Sample Preparation for Small Angle X-ray Scattering Studies: The materials were filled into $1 \mathrm{~mm}$ diameter quartz X-ray tubes, which were then mounted into a custombuilt aluminium cassette that allowed X-ray detection with $\pm 13.5^{\circ}$ angular range. The cassette fits into a standard hot stage (Instec model HCS402) that allowed temperature control with $\pm 0.01^{\circ} \mathrm{C}$ precision. The stage also included two cylindrical neodymium iron boron magnets that supplied a magnetic induction of $H=1.5 \mathrm{~T}$ at the position of the X-ray capillary. The magnetic field direction is perpendicular to the incident X-ray beam. Two-dimensional SAXS images were recorded on a Princeton Instruments $2084 \times 2084$ pixel array $\mathrm{CCD}$ detector in the $\mathrm{X} 6 \mathrm{~B}$ beamline at the National Synchrotron Light Source. The beamline was configured for a collimated beam $(0.2 \mathrm{~mm} \times 0.3 \mathrm{~mm})$ at energy $16 \mathrm{keV}(0.775 \AA)$. Details of the experimental conditions 
are described elsewhere.[98]

\section{Acknowledgements}

This work was supported by the DOE under Grant DE-FG02-06ER 46331 (optical, TEM, and polarizing microscopy studies) and the NSF under Grant DMR-0964765 and DMR-1307674 (XRD studies).

\section{References}

[1] de Gennes PG, Prost J. The physics of liquid crystals. Oxford: Clarendon Press; 1993.

[2] Imrie CT, Henderson PA. Liquid crystal dimers and higher oligomers: between monomers and polymers. Chem. Soc. Rev. 2007; 36: 2096-2124.

[3] Panov VP, Nagaraj M, Vij JK, Panarin YP, Kohlmeier A, Tamba MG, Lewis RA, Mehl GH. Spontaneous periodic deformations in nonchiral planar-aligned bimesogens with a nematic-nematic transition and a negative elastic constant. Phys. Rev. Lett. 2010; 105: 167801.

[4] Panov VP, Balachandran R, Nagaraj M, Vij JK, Tamba MG, Kohlmeier A, Mehl GH. Microsecond linear optical response in the unusual nematic phase of achiral bimesogens. Appl. Phys. Lett. 2011; 99: 261903.

[5] Henderson PA, Imrie CT. Methylene-linked liquid crystal dimers and the twist-bend nematic phase. Liq. Cryst. 2011; 38: 1407-1414.

[6] Cestari M, Frezza E, Ferrarini A, Luckhurst GR. Crucial role of molecular curvature for the bend elastic and flexoelectric properties of liquid crystals: mesogenic dimers as a case study. J. Mater. Chem. 2011; 21: 12303.

[7] Panov VP, Balachandran R, Vij JK, Tamba MG, Kohlmeier A, Mehl GH. Fieldinduced periodic chiral pattern in the $\mathrm{N}_{\mathrm{x}}$ phase of achiral bimesogens. Appl. Phys. Lett. 2012; 101: 234106.

[8] Beguin L, Emsley JW, Lelli M, Lesage A, Luckhurst GR, Timimi BA, Zimmermann H. The chirality of a twist-bend nematic phase identified by NMR spectroscopy. J. Phys. Chem. B 2012; 116: 7940-7951.

[9] Adlem K, Copic M, Luckhurst GR, Mertelj A, Parri O, Richardson RM, Snow BD, Timimi BA, Tuffin RP, Wilkes D. Chemically induced twist-bend nematic liquid crystals, liquid crystal dimers, and negative elastic constants. Phys. Rev. E 2013; 88: 022503.

[10] Meyer C, Luckhurst GR, Dozov I. Flexoelectrically driven electroclinic effect in the twist-Bend nematic phase of achiral molecules with bent shapes. Phys. Rev. Lett. 
2013; 111: 067801 .

[11] Meyer RB. Molecular fluids les houches lectures. Gordon and Breach; 1973.

[12] Dozov I. On the spontaneous symmetry breaking in the mesophases of achiral banana-shaped molecules. Europhys. Lett. 2001; 56: 247.

[13] Memmer R. Liquid crystal phases of achiral banana-shaped molecules: a computer simulation study. Liq. Cryst. 2002; 29: 483-496.

[14] Shamid SM, Dhakal S, Selinger JV. Statistical mechanics of bend flexoelectricity and the twist-bend phase in bent-core liquid crystals. Phys. Rev. E 2013; 87: 052503.

[15] Chen D, Porada JH, Hooper JB, Klittnick A, Shen Y, Tuchband MR, Korblova E, Bedrov D, Walba DM, Glaser MA, Maclennan JE, Clark NA. Chiral heliconical ground state of nanoscale pitch in a nematic liquid crystal of achiral molecular dimers. Proc. Natl. Acad. Sci. 2013; 110: 15931-15936.

[16] Borshch V, Kim Y-K, Xiang Y, Gao M, Jákli A, Panov VP, Vij JK, Imrie CT, Tamba MG, Mehl GH, Lavrentovich OD. Nematic twist-bend phase with nanoscale modulation of molecular orientation. Nat. Commun. 2013; 4: 2635.

[17] Yu LJ, Saupe A. Observation of a biaxial nematic phsae in potassium laurate-1decanol-water mixtures. Phys. Rev. Lett. 1980; 45: 1000-1003.

[18] Galerne Y. Vanishing disclination lines in lyotropic biaxial nematics. Mol. Cryst. Liq. Cryst. 1997; 292: 103-112.

[19] de Melo Filho AA, Laverde A, Fujiwara FY. Observation of two biaxial nematic mesophases in the tetradecyltrimethylammonium bromide/decanol/water system. Langmuir 2003; 19: 1127-1132.

[20] Santoro PA, Sampaio AR, da Luz HLF, Palangana AJ. Temperature dependence of refractive indices near uniaxial-biaxial nematic phase transition. Phys. Lett. A 2006; 353: 512-515.

[21] Braga WS, Kimura NM, Luders DD, Sampaio AR, Santoro PA, Palangana AJ. Reentrant isotropic-calamitic nematic phase transition in potassium laurate-decanolD2O mixtures. Eur. Phys. J. E. 2007; 24: 247-250.

[22] Amaral LQ. Micelles forming biaxial lyotropic nematic phases. Liq. Cryst. 2010; 37: 627-640.

[23] Braga WS, Santos OR, Sampaio AR, Kimura NM, Simoes M, Palangana AJ. An optical conoscopy study of a reentrant discotic nematic-biaxial nematic phase transition. J. Mol. Liq. 2012; 170: 72-75.

[24] Akpinar E, Reis D, Figueiredo Neto AM. Effect of alkyl chain length of alcohols on nematic uniaxial-to biaxial phase transitions in a potassium laurate/alcohol/ $/ \mathrm{K}_{2} \mathrm{SO}_{4} /$ water lyotropic mixture. Liq. Cryst. 2012; 39: 881-888.

[25] Braga WS, Santos OR, Luders DD, Sampaio AR, Kimura NM, Simoes M, 
Palangana AJ. Conoscopic image of a biaxial negative nematic phase in a potassium laurate-decanol-D2O mixture. J. Mol. Liq. 2013; 187: 20-23.

[26] Reis D, Akpinar E, Figueiredo Neto AM. Effect of alkyl chain length of alcohols on cholesteric uniaxial to cholesteric biaxial phase transitions in a potassium laurate/alcohol/potassium sulfate/water/brucine lyotropic mixture: Evidence of a firstorder phase transition. J. Phys. Chem. B 2013; 117: 942-948.

[27] Akpinar E, Reis D, Figueiredo Neto AM. Study of the cholesteric-to-cholesteric phase transitions on the lyotropic mixture of $\mathrm{Kl} / \mathrm{K}_{2} \mathrm{SO}_{4} / 1$-undecanol/water/brucine presenting the cholesteric biaxial phase. Mol. Cryst. Liq. Cryst. 2013; 576: 98-105.

[28] Berejnov V, Cabuil V, Perzynski R, Raikher Y. Lyotroic system potassium laurate/1-decanol/water as a carrier medium for a ferronematic liquid crystal: phase diagram study. J. Phys. Chem. B 1998; 102: 7132-7138.

[29] Berejnov VV, Cabuil V, Perzynski R, Raikher YL, Lysenko SN, Sdobnov VN. Lyotropic nematogenic system potassium laurate-1-decanol-water: method of synthesis and study of phase diagrams. Crystallogr. Rep. 2000; 45: 493-500.

[30] Acharya BR, Primak A, Dingemans TJ, Samulski ET, Kumar S. The elusive thermotropic biaxial nematic phase in rigid bent-core molecules. Pramana- J. Phys. 2003; 61: 231-237.

[31] Acharya BR, Primak A, Kumar S. Biaxial nematic phase in bent-core thermotropic mesogens. Phys. Rev. Lett. 2004; 92: 145506.

[32] Madsen LA, Dingemans TJ, Nakata M, Samulski ET. Thermotropic biaxial nematic liquid crystals. Phys. Rev. Lett. 2004; 92: 145505.

[33] Lee J-H, Lim T-K, Kim W-T, Jin J-I. Dynamics of electro-optical switching processes in surface stabilized biaxial nematic phase found in bent-core liquid crystal. J. Appl. Phys. 2007; 101: 034105.

[34] You J, Jung JY, Rhie K, Pergamenshchik VM, Shin S-T. Macroscopic properties of the nematic phase of boomerang-shaped "C7": Evidence of biaxiality. J. Kor. Phys. Soc. 2008; 52: 342-349.

[35] Lee GS, Cho JS, Kim JC, Yoon T-H, Shin S-T. Direct confirmation of biaxiality in a bent-core mesogen through the measurement of electro-optic characteristics. J. Appl. Phys. 2009; 105: 094509.

[36] Nagaraj M, Merkel K, Vij JK, Kocot A. Macroscopic biaxiality and electric-fieldinduced rotation of the minor director in the nematic phase of a bent-core liquid crystal. EPL 2010; 91: 66002.

[37] Picken SJ, Dingemans TJ, Madsen LA, Francescangeli O, Samulski ET. Uniaxial to biaxial nematic phase transition in a bent-core thermotropic liquid crystal by polarising microscopy. Liq. Cryst. 2012; 39: 19-23.

[38] Senyuk B, Kim Y-K, Tortora L, Shin S-T, Shiyanovskii SV, Lavrentovich OD. Surface alignment, anchoring transitions, optical properties and topological defects in 
nematic bent-core materials C7 and C12. Mol. Cryst. Liq. Cryst. 2011; 540: 20-41.

[39] Ostapenko T, Zhang C, Sprunt SN, Jákli A, Gleeson JT. Magneto-optical technique for detecting the biaxial nematic phase. Phys. Rev. E 2011; 84: 021705.

[40] Prasad V, Kang S-W, Suresh KA, Joshi L, Wang Q, Kumar S. Thermotropic uniaxial and biaxial nematic and smectic phases in bent-core mesogens. J. Am. Chem. Soc. 2005; 127: 17224-17227.

[41] Dong RY, Kumar S, Prasad V, Zhang J. High nematic ordering in a bent-core smectogen showing a biaxial nematic phase: A ${ }^{13} \mathrm{C}$ NMR study. Chem. Phys. Lett. 2007; 448: 54-60.

[42] Yoon HG, Kang S-W, Dong RY, Marini A, Suresh KA, Srinivasarao M, Kumar S. Nematic biaxiality in a bent-core material. Phys. Rev. E 2010; 81: 051706.

[43] Yoon HG, Kang S-W, Lehmann M, Park JO, Srinivasarao M, Kumar S. Homogeneous and homeotropic alignment of bent-core uniaxial and biaxial nematic liquid crystals. SoftMatter 2011; 7: 8770.

[44] Park MS, Yoon B-J, Park JO, Prasad V, Kumar S, Srinivasarao M. Raman scattering study of phase biaxiality in a thermotropic bent-core nematic liquid crystal. Phys. Rev. Lett. 2010; 105: 027801.

[45] Dong RY, Marini A. Conformational Study of a Bent-Core Liquid Crystal: 13C NMR and DFT Computation Approach. J. Phys. Chem. B 2009; 113: 14062-14072.

[46] Aluculesei A, Vaca Chavez F, Cruz C, Sebastiao PJ, Nagaveni NG, Prasad V, Dong RY. Proton NMR Relaxation Study on the Nematic-Nematic Phase Transition in A131 Liquid Crystal. J. Phys. Chem. B 2012; 116: 9556-9563.

[47] Mathew M, Kang SW, Kumar S, Li Q. Designing bent-core nematogens towards biaxial nematic liquid crystals. Liq. Cryst. 2011; 38: 31-40.

[48] Le KV, Mathew M, Chambers M, Harden J, Li Q, Takezoe H, Jákli A. Electrooptic technique to study biaxility of liquid crystals with positive dieelctric anisotropy: the case of a bent-core material. Phys. Rev. E 2009; 79: 030701.

[49] Senyuk B, Wonderly H, Mathews M, Li Q, Shiyanovskii SV, Lavrentovich OD. Surface alignment, anchoring transitions, optical properties, and topological defects in the nematic phase of thermotropic bent-core liquid crystal A131. Phys. Rev. E 2010; 82: 041711.

[50] Kim Y-K, Senyuk B, Shin S-T, Kohlmeier A, Mehl GH, Lavrentovich OD. Surface alighment, anchoring transitions, optical properties, and topological defects in the thermotropic nematic phase of organo-siloxane tetrapodes. Soft Matter 2014; 10: 500509.

[51] Kim Y-K, Majumdar M, Senyuk BI, Tortora L, Seltmann J, Lehmann M, Jákli A, Gleeson HF, Lavrentovich OD, Sprunt S. Search for biaxiality in a shape-persistent bent-core nematic liquid crystal. Soft Matter 2012; 8: 8880-8890. 
[52] Kim Y-K, Senyuk B, Lavrentovich OD. Molecular reorientation of a nematic liquid crystal by thermal expansion. Nat. Commun. 2012; 3: 1133.

[53] Southern CD, Brimicombe PD, Siemianowski SD, Jaradat S, Roberts N, Gortz V, Goodby JW, Gleeson HF. Thermotropic biaxial nematic order parameters and phase transitions deduced by Raman scattering. EPL 2008; 82: 56001.

[54] Xiang Y, Goodby JW, Gortz V, Gleeson HF. Revealing the uniaxial to biaxial nematic liquid crystal phase transition via distinctive electroconvection. Appl. Phys. Lett. 2009; 94: 193507.

[55] Yelamaggad CV, Prasad SK, Nair GG, Shashikala IS, Rao DSS, Lobo CV, Chandrasekhar S. A low-molar-mass, monodispersive, bent-rod dimer exhibiting biaxial nematic and smectic A phases. Angew. Chem. Int. Ed. 2004; 43: 3429-3432.

[56] Prasad SK, Nair GG, Rao DSS, Lobo CV, Shashikala I, Yelamaggad CV. Biaxial Nematic and Smectic A Phases in a "Peelable Banana-Shaped" Molecule. Mol. Cryst. Liq. Cryst. 2005; 437: 211-221.

[57] Seltmann J, Muller K, Klein S, Lehmann A. V-shaped nematogens with the "magic bent angle". Chem. Commun. 2011; 47: 6680-6682.

[58] Lehmann M. Biaxial nematics from their prediction to the materials and the vicious circle of molecular design. Liq. Cryst. 2011; 38: 1389-1405.

[59] Lehmann M, Kang S-W, Köhn C, Haseloh S, Kolb U, Schollmeyer D, Wang Q, Kumar S. Shape-persistent V-shaped mesogens-formation of nematic phases with biaxial order. J. Mater. Chem. 2006; 16: 4326-4334.

[60] Lehmann M, Köhn C, Figueirinhas JL, Feio G, Cruz C, Dong RY. Biaxial nematic mesophases from shape-persistent mesogens with a fluorenone bending unit. Chem. Eur. J. 2010; 16: 8275-8279.

[61] Figueirinhas JL, Feio G, Cruz C, Lehmann M, Kohn C, Dong RY. Nuclear magnetic resonance spectroscopic investigations of phase biaxiality in the nematic glass of a shape-persistent V-shaped mesogen. J. Chem. Phys. 2010; 133: 174509.

[62] Tschierske C, Photinos DJ. Biaxial nematic phases. J. Mat. Chem. 2010; 20: 42634294.

[63] Jákli A. Liquid crystals of the twenty-first century-nematic phase of bent-core molecules. Liq. Cryst. Rev. 2013; 1: 65-82.

[64] Lehmann M, Kohn C, Kresse H, Vakhovskaya Z. Synthesis and properties of oxadiazole based V-shaped, shape persistent nematogens. Chem. Chommun. 2008; $1768-1770$.

[65] Lehmann M, Seltmann J, Auer AA, Prochnow E, Benedikt U. Synthesis and mesomorphic properties of new $\mathrm{V}$-shaped shape-persistent nematogens containing a thiazole or a thiadiazole bending unit. J. Mater. Chem. 2009; 19: 1978-1988.

[66] Merkel K, Kocot A, Vij JK, Korlacki R, Mehl GH, Meyer T. Thermotropic biaxial 
nematic phase in liquid crystalline organo-siloxane tetrapodes. Phys. Rev. Lett. 2004; 93: 237801.

[67] Neupane K, Kang SW, Sharma S, Carney D, Meyer T, Mehl GH, Allender DW, Kumar S, Sprunt S. Dynamic light scattering study of biaxial ordering in a thermotropic liquid crystal. Phys. Rev. Lett. 2006; 97: 207802.

[68] Kocot A, Vij JK. Study of the biaxiality in the nematic phase of liquid crystals in terms of orientational order parameters by infrared spectroscopy. Liq. Cryst. 2010; 37: 653-667.

[69] Filip D, Cruz C, Sebastiao PJ, Cardoso M, Ribeiro AC, Vilfan M, Meyer T, Kouwer PHJ, Mehl GH. Phase structure and molecular dynamics of liquid-crystalline side-on organosiloxane tetrapodes. Phys. Rev. E 2010; 81: 011702.

[70] Merkel K, Kocot A, Vij JK, Mehl GH, Meyer T. The orientational order parameters of a dendritic liquid crystal organo-siloxane tetrapode oligomer, determined using polarized infrared spectroscopy. J. Chem. Phys. 2004; 121: 5012-5021.

[71] Merkel K, Nagaraj M, Kocot A, Kohlmeier A, Mehl GH, Vij JK. Biaxial order and a rotation of the minor director in the nematic phase of an organo-siloxane tetrapode by the electric field. J. Chem. Phys. 2012; 136: 094513.

[72] Li J-F, Percec V, Rosenblatt C. Nearly-second-order nematic-isotroic phase transition in a cyclic thermotropic liquid crystal. Phys. Rev. E 1993; 48: R1-R4.

[73] Syed IM, Percec V, Petschek RG, Rosenblatt C. Apparent tricritical behavior at a nearly second-order nematic-isotropic phase transition of a cyclic liquid crystalline trimer. Phys. Rev. E 2003; 67: 011704.

[74] Li J-F, Percec V, Rosenblatt C, Lavrentovich OD. Biaxiality in a cyclic thermotropic nematic liquid-crystal. Europhys. Lett. 1994; 25: 199-204.

[75] Olivares JA, Stojadinovic S, Dingemans TJ, Sprunt S, Jákli A. Optical studies of the nematic phase of an oxazole-derived bent-core liquid crystal. Phys. Rev. E 2003; 68: 041704.

[76] Stannarius R, Eremin A, Tamba M-G, Pelzl G, Weissflog W. Field-induced texture transitions in a bent-core nematic liquid crystal. Phys. Rev. E 2007; 76: 061704.

[77] Jang Y, Panov VP, Kocot A, Vij JK, Lehmann A, Tschierske C. Optical confirmation of biaxial nematic phase in a bent-core mesogen. Appl. Phys. Lett. 2009; 95: 183304.

[78] Nagaraj M, Panarin YP, Manna U, Vij JK, Keith C, Tschierske C. Electric field induced biaxiality and the electro-optic effect in a bent-core nematic liquid crystal. Appl. Phys. Lett. 2010; 96: 011106.

[79] Sreenilayam SP, Nagaraj M, Panarin YP, Vij JK, Keith C, Tschierske C. Dielectric and Optical Study of Biaxial Bent-Core Nematic Liquid Crystal. Mol. Cryst. Liq. Cryst. 2011; 540: 75-81. 
[80] Elamain O, Hegde G, Fodor-Csorba K, Komitov L. Field-induced optically isotropic state in bent core nematic liquid crystals: unambiguous proof of field-induced optical biaxiality. J. Phys. D: Appl. Phys. 2013; 46: 455101.

[81] Borshch V, Shiyanovskii SV, Lavrentovich OD. Electric Field Induced Biaxial Order and Differential Quenching of Uniaxial Fluctuations in a Nematic with Negative Dielectric Anisotropy. Mol Cryst Liq Cryst 2012; 559: 97-105.

[82] Borshch V, Shiyanovskii SV, Lavrentovich OD. Nanosecond electro-optic switching of a liquid crystal. Phys. Rev. Lett. 2013; 111: 107802.

[83] Luckhurst GR. Biaxial nematic liquid crystals: Fact or fiction? Thin Silid Films 2001; 393: 40-52.

[84] Huh S-M, Jin J-I, Achard M-F, Hardouin F. Synthesis and liquid crystalline properties of new h-haped twin compounds: a series of Liq. Cryst. 1999; 26: 919-924.

[85] Zhang Y, Perdiguero JM, Baumeister U, Walker C, Etxebarria J, Prehm M, Ortega J, Tschierske C, O'callaghan MJ, Harant A, Handschy M. Laterally azo-bridged Hshaped ferroelectric dimesogens for second order nonlinear optics. J. Am. Chem. Soc. 2009; 131: 18386-18392.

[86] Kolpaczynska M, Madrak K, Mieczkowski J, Gorecka E, Pociecha D. H-shaped liquid crystalline dimers. Liq. Cryst. 2011; 38: 149-154.

[87] Varia MC, Kumar S, Prajapati AK. H-shaped azoester-oxymethylene containing twin liquid crystalline compounds. Liq. Cryst. 2012; 39: 365-371.

[88] Prajapati AK, Varia MC. H-shaped symmetrical twin liquid crystalline compounds with polar-terminal substituents. Liq. Cryst. 2013; 40: 1151-1158.

[89] Kleman M, Lavrentovich OD. Soft matter physics: An introduction. New York: Springer; 2003.

[90] Oldenbourg R. Polarization microscopy with the LC-polscope. Cold Spring Harbor: Cold Spring Harbor Laboratory Press; 2005.

[91] Lavrentovich OD. Looking at the world through liquid crystal glasses. Contemp. Math 2012; 577: 25.

[92] Kim Y-K, Shiyanovskii SV, Lavrentovich OD. Morphogenesis of defects and tactoids during isotropic nematic phase transition in self assembled lyotropic chromonic liquid crystals. J. Phys.: Condens. Matter. 2013; 25: 404202.

[93] Volovik GE, Lavrentovich OD. Topological dynamics of defects: Boojums in nematic drops. Zh. Eksp. Teor. Fiz. 1983; 95: 1997-2010 or Sov. Phys. JETP. 1983; 58: $1159-1167$.

[94] Lavrentovich OD. Topological defects in dispersed words and worlds around liquid crystals, or liquid crystal drops. Liq. Cryst. 1998; 24: 117-125.

[95] Kim Y-K, Majumdar M, Senyuk BI, Tortora L, Seltmann J, Lehmann M, Jákli A, 
Gleeson JT, Lavrentovich OD, Sprunt S. Search for biaxiality in a shape-persistent bentcore nematic liquid crystal. Soft Matter 2012; 8: 8880-8890.

[96] Poulin P, Stark H, Lubensky TC, Weitz DA. Novel colloidal interactions in anisotropic fluids. Science 1997; 275: 1770-1773.

[97] Candau S, Le Roy P, Debeauvais F. Magnetic field effects in nematic and cholesteric droplets suspended in an isotropic liquid. Mol. Cryst. Liq. Cryst. 1973; 23: 283-297.

[98] Hong SH, Verduzco R, Williams JC, Twieg RJ, Dimasi E, Pindak R, Jákli A, Gleeson JT, Sprunt S. Short-range smectic order in bent-core nematic liquid crystals. Soft Matter 2010; 6: 4819-4827.

[99] Francescangeli O, Samulski ET. Insights into the cybotactic nematic phase of bentcore molecules. Soft Matter 2010; 6: 2413-2420.

[100] Zhang C, Gao M, Diorio N, Weissflog W, Baumeister U, Sprunt S, Gleeson JT, Jákli A. Direct observation of smectic layers in thermotropic liquid crystals. Phys. Rev. Lett. 2012; 109: 107802.

[101] Zhang C, Sadashiva BK, Lavrentovich OD, Jákli A. Cryo-TEM studies of two smectic phases of an asymmetric bent-core material. Liq. Cryst. 2013; 40: 1636-1645. 
(a)

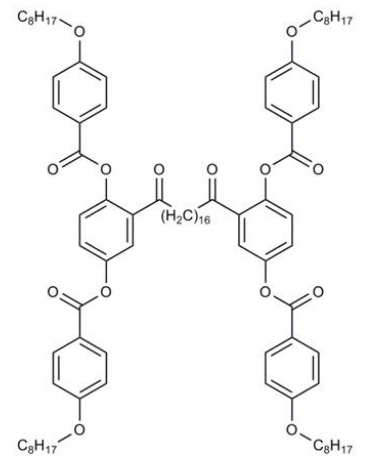

(b)

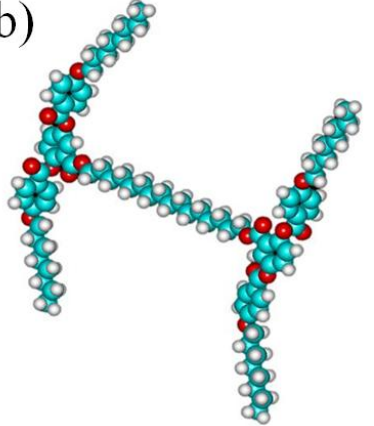

(c)

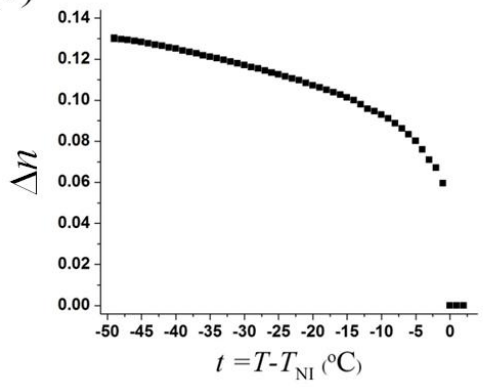

Figure 1. (a) Chemical structure and (b) space filling model of H-shaped RB01189

molecules. (c) Birefringence of RB01189 measured in the planar AL1 cell as a function of effective $t=T-T_{\mathrm{NI}}$.
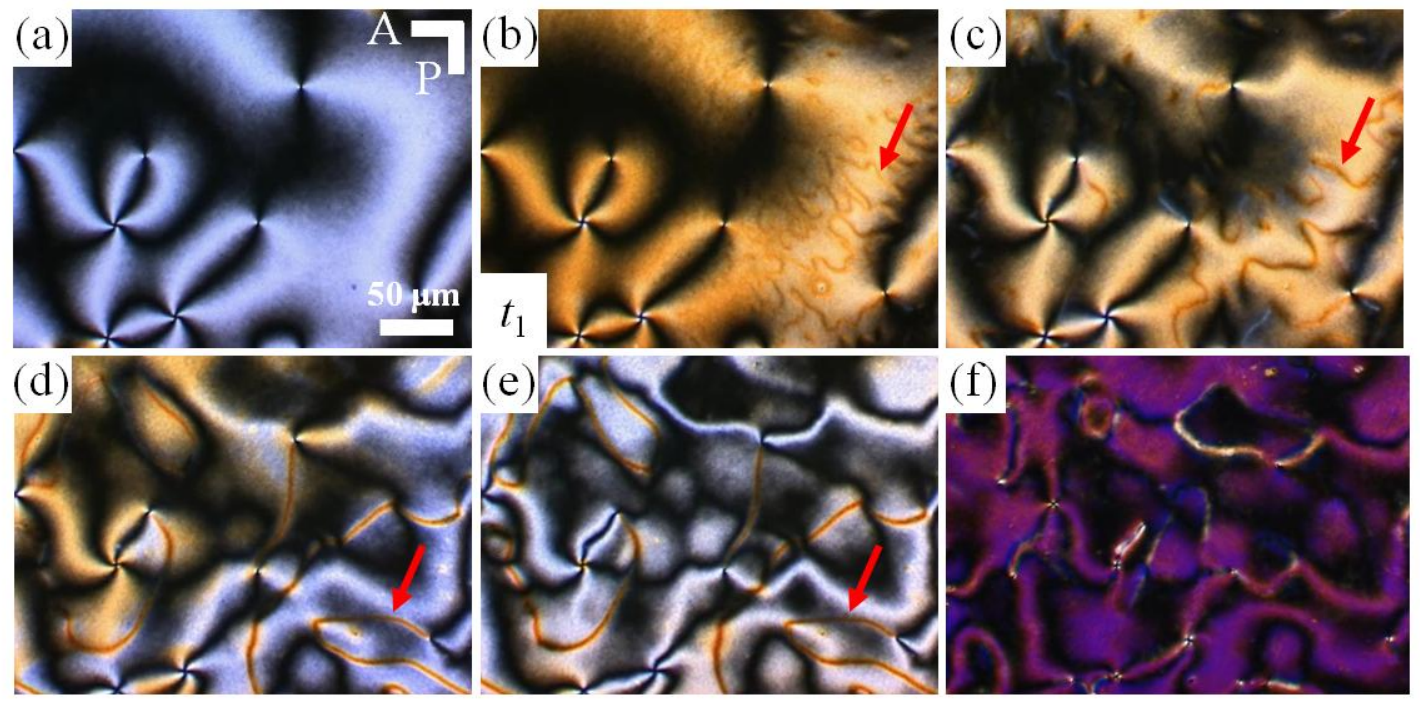

Figure 2. (Colour on-line) Sequence of textures in the AL2 cell $(d=6 \mu \mathrm{m})$ at (a) $t=-1^{\circ} \mathrm{C}\left(T=107^{\circ} \mathrm{C}\right),(\mathrm{b})-1.8^{\circ} \mathrm{C}\left(=t_{1}\right),(\mathrm{c})-2^{\circ} \mathrm{C},(\mathrm{d})-2.3^{\circ} \mathrm{C},(\mathrm{e})-2.5^{\circ} \mathrm{C}$, and (f) $-4^{\circ} \mathrm{C}$; $\mathrm{A}$ and $\mathrm{P}$ indicate analyzer and polarizer, respectively; arrows point towards the domain walls. 

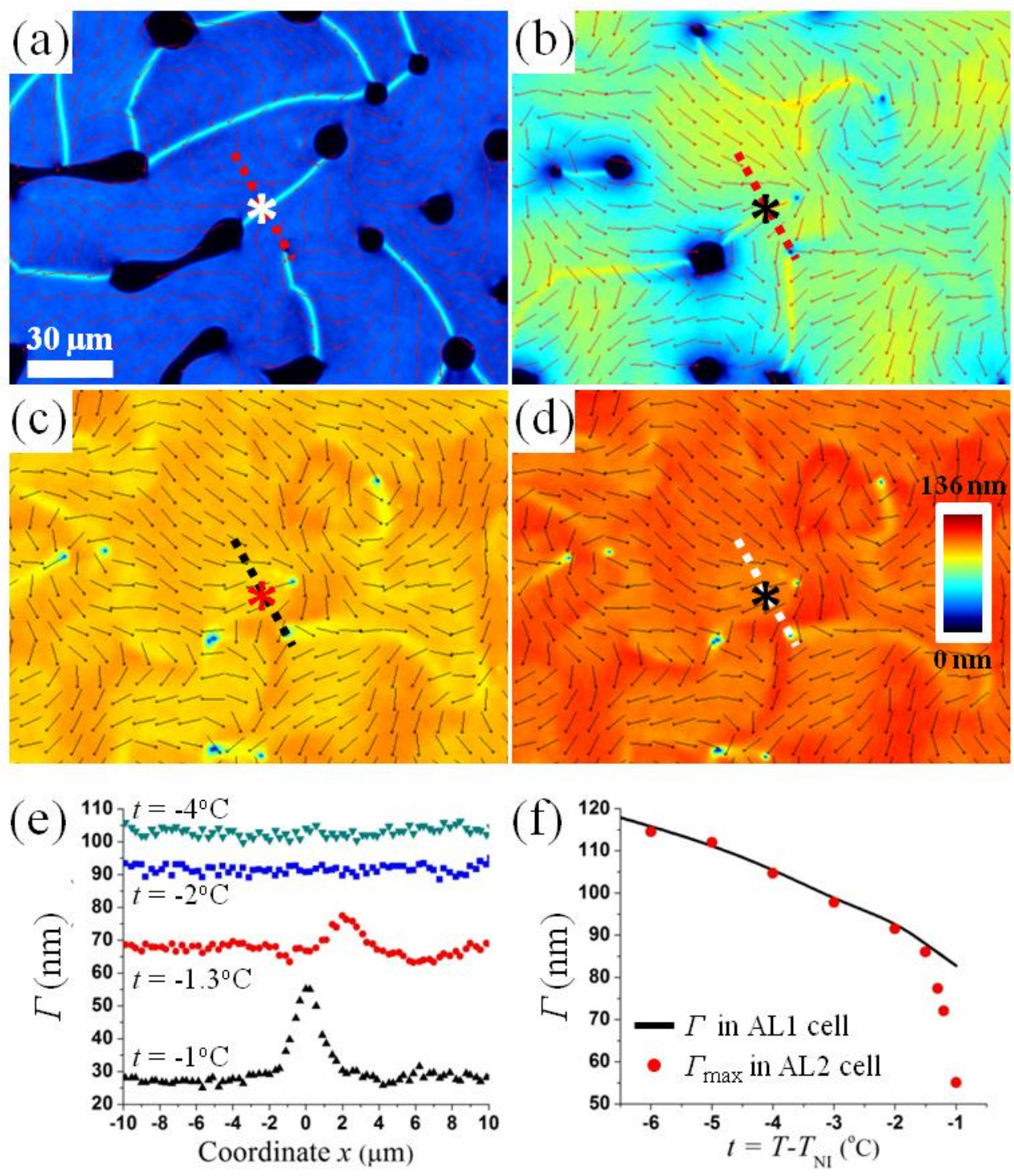

Figure 3. (Colour on-line) Retardation maps in the AL2 cell $(d=1.4 \mu \mathrm{m})$ at (a) $t=-1^{\circ} \mathrm{C}\left(<t_{1}\right),(\mathrm{b})-1.3^{\circ} \mathrm{C}$, (c) $-2^{\circ} \mathrm{C}$, and (d) $-4^{\circ} \mathrm{C}$; grids represent the director $\hat{\mathbf{n}}$. (e) Measured $\Gamma$ along the dotted lines in a-d. (f) Comparison of $\Gamma=d \Delta n$ for $d=1.4 \mu \mathrm{m}$ ( $\Delta n$ data are measured experimentally in planar cell, Figure 1c) and $\Gamma_{\max }$ (measured at the center of the DW marked $*$ in a-d) in the AL2 cell of thickness $d=1.4 \mu \mathrm{m}$. 


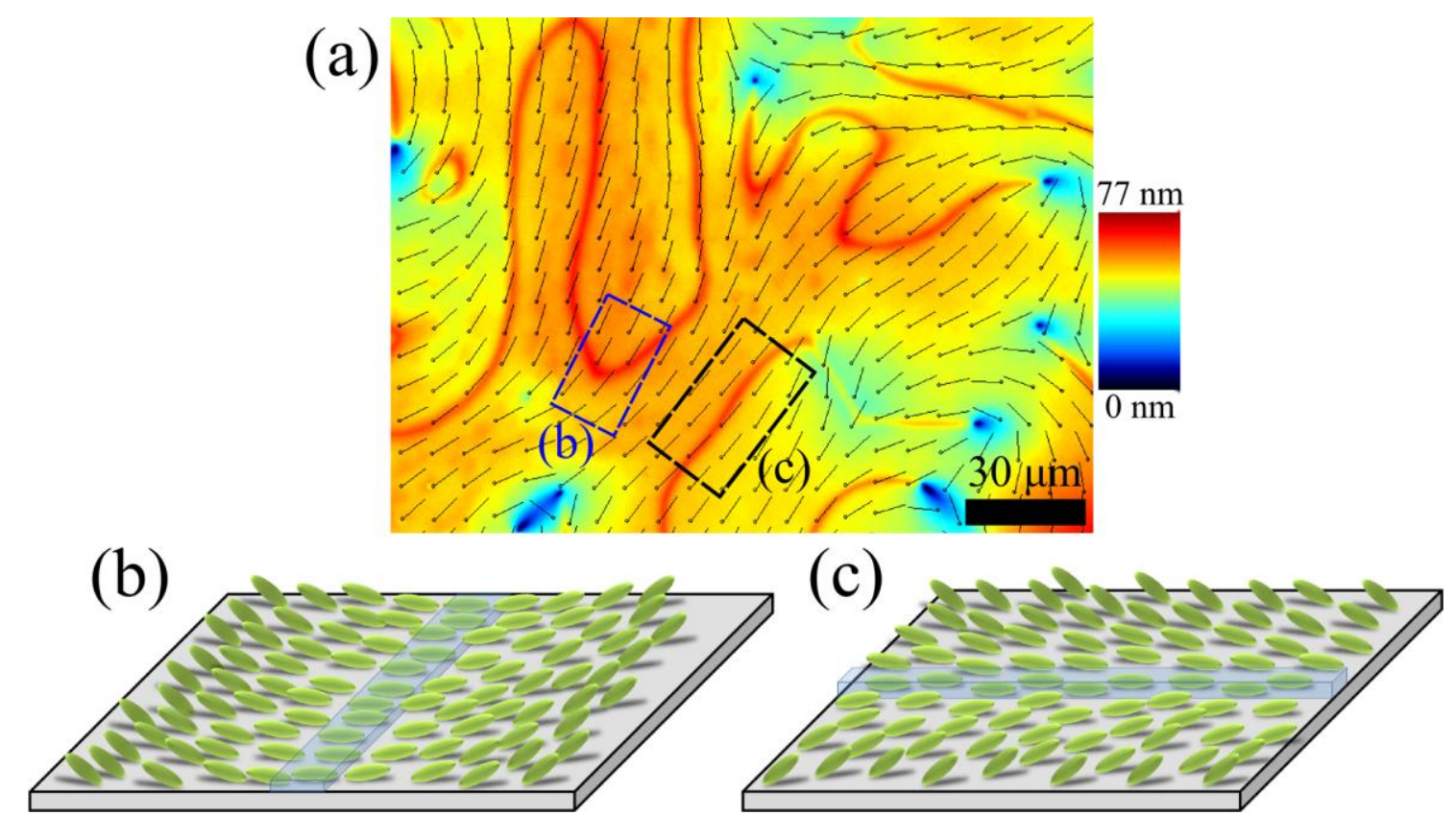

Figure 4. (Colour on-line) (a) Retardation map with the director field projected onto the plane of the cell in the AL2 cell $(d=1.1 \mu \mathrm{m})$ at $t=-1.4^{\circ} \mathrm{C}\left(<t_{1}\right)$; black grids indicate the director $\hat{\mathbf{n}}$. Director configurations for (b) bend-splay and (c) twist DW. 


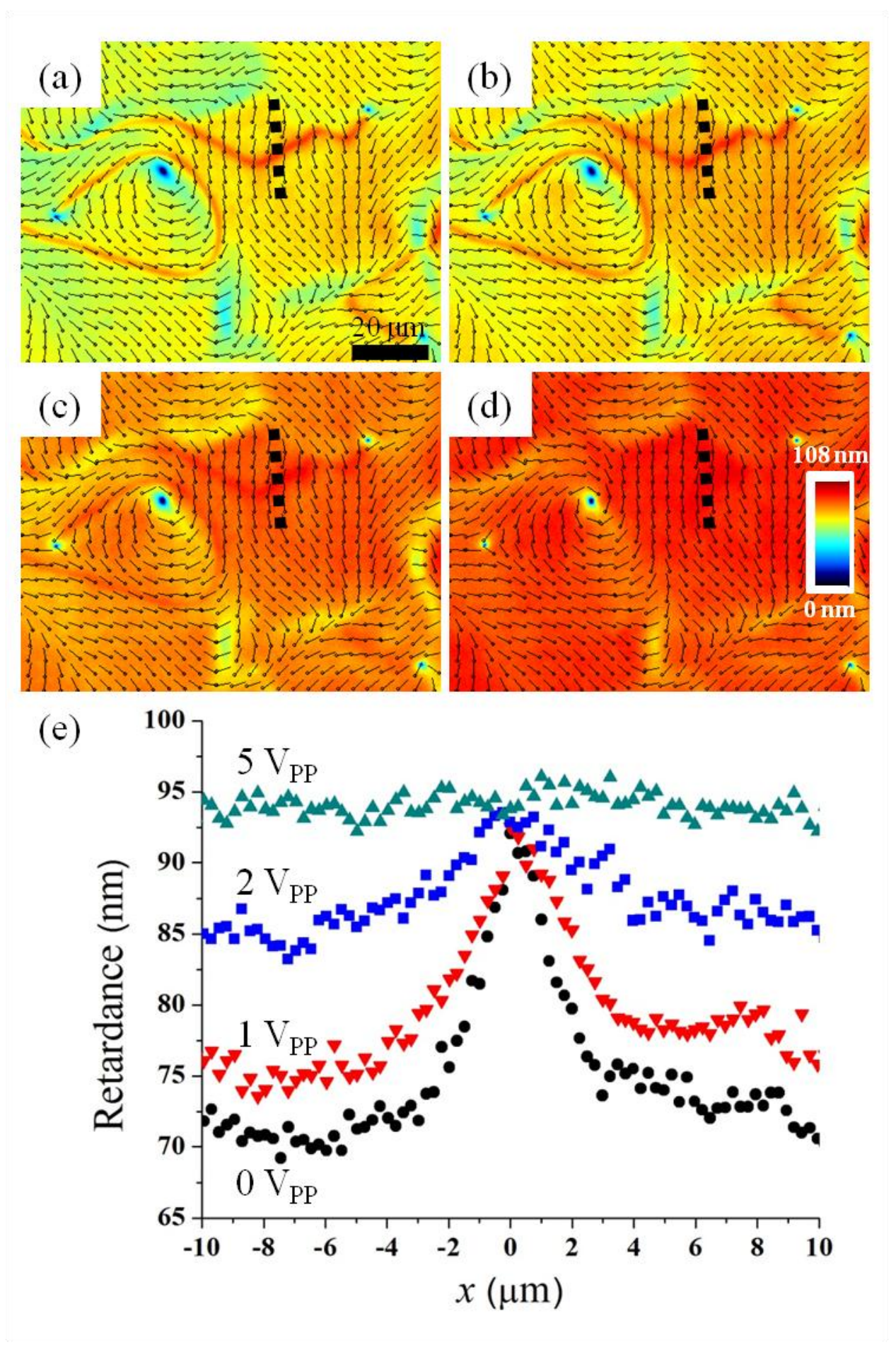

Figure 5. (Colour on-line) Retardation maps of the AL2 cell $(d=1.4 \mu \mathrm{m})$ at $t=-1.5^{\circ} \mathrm{C}$ with the vertical electric field of (a) 0 , (b) 1 , (c) 2 , and (d) $5 \mathrm{~V}_{\mathrm{PP}}$; grids map the director $\hat{\mathbf{n}}$. (e) Retardance across DW (along dashed lines). 

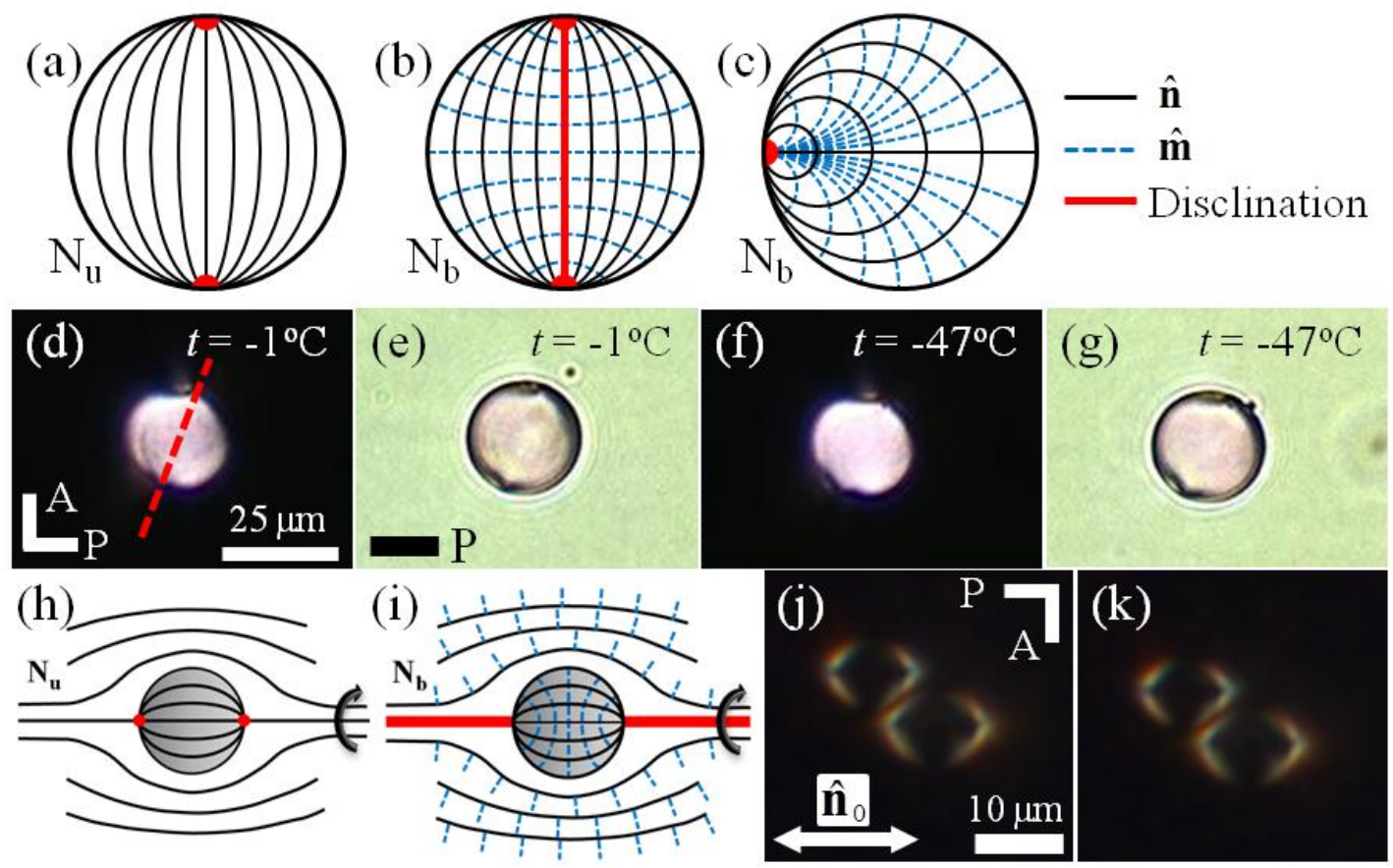

Figure 6. (Colour on-line) (a) $\mathrm{N}_{\mathrm{u}}$ bipolar droplet with two point defect-boojums. $\mathrm{N}_{\mathrm{b}}$ bipolar droplets (b) with a singular disclination $m=1$ (red bold line) formed by secondary director $\hat{\mathbf{m}}$ and (c) with a single boojum of strength $m=2$. (d-g) $\mathrm{N}_{\mathrm{u}}$ bipolar droplet of RB01189 in a glycerol at (d, e) $t=-1^{\circ} \mathrm{C}\left(T=107^{\circ} \mathrm{C}\right)$, and (f, g) $-47^{\circ} \mathrm{C}$; dashed line indicates the droplet symmetry axis. (h-k) Scheme of director configuration around colloids in (h) $\mathrm{N}_{\mathrm{u}}$ and (i) $\mathrm{N}_{\mathrm{b}}$. Chain of colloids with the $\mathrm{N}_{\mathrm{u}}$ bipolar structure in AL1 cell $(d=20 \mu \mathrm{m})$ at $(\mathrm{j}) t=-1^{\circ} \mathrm{C}$ and $(\mathrm{k})-47^{\circ} \mathrm{C}$. 
(a)

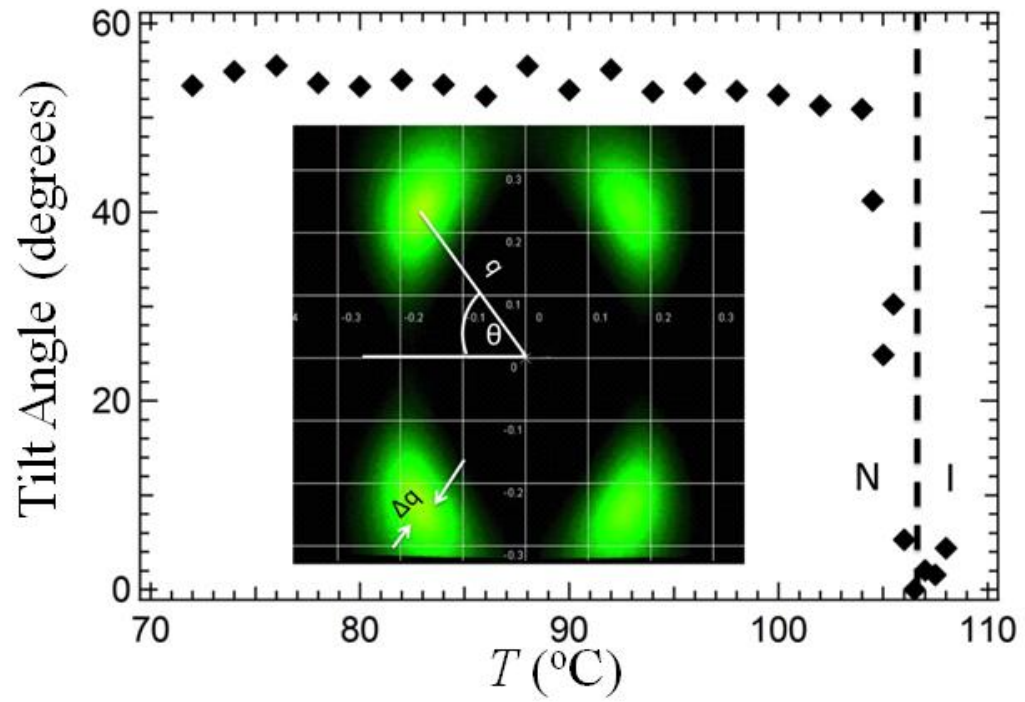

(b)

(c)
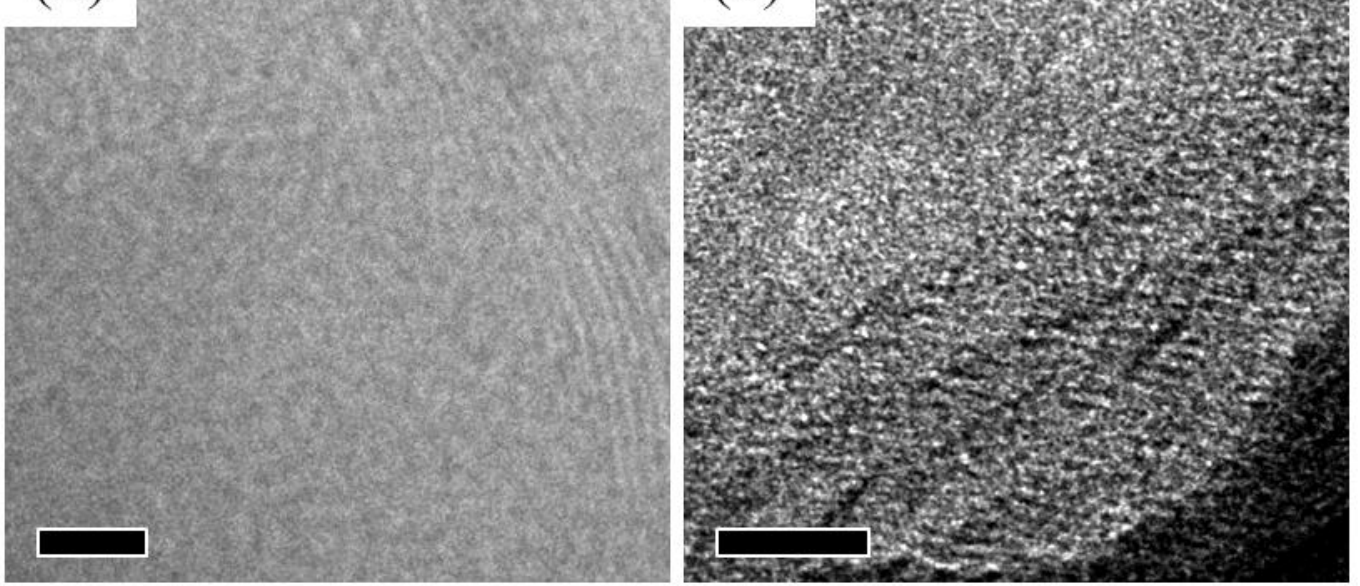

Figure 7. (a) Temperature dependence of the tilt angle of the smectic clusters in the $\mathrm{N}$ phase of RB01189. The inset shows SAXS pattern at $T=75^{\circ} \mathrm{C}$. (b,c) Direct images of the smectic nanoclusters taken by (b) Cryo-TEM and (c) freeze-fracture TEM; sample was quenched at $75^{\circ} \mathrm{C}$. Scale bar is $25 \mathrm{~nm}$. 
Supplementary Information

\section{Properties of the Nematic Phase of a Laterally Linked H-Shaped Liquid Crystal} Dimer

Young-Ki Kim, ${ }^{a}$ Randall Breckon, ${ }^{b}$ Saonti Chakraborty, ${ }^{b}$ Min Gao, ${ }^{a}$ Samuel N. Sprunt,${ }^{c}$ James T. Gleeson, ${ }^{c}$ Robert J. Twieg, ${ }^{b}$ Antal Jákli, ${ }^{a}$ Oleg D. Lavrentovich ${ }^{a}$

${ }^{a}$ Liquid Crystal Institute and Chemical Physics Interdisciplinary Program, Kent State University, Kent, OH 44242 , USA.

${ }^{b}$ Department of Physics, Kent State University, Kent, OH 44242, USA.

${ }^{c}$ Department of Chemistry \& Biochemistry, Kent State University, Kent, OH 44242, USA.
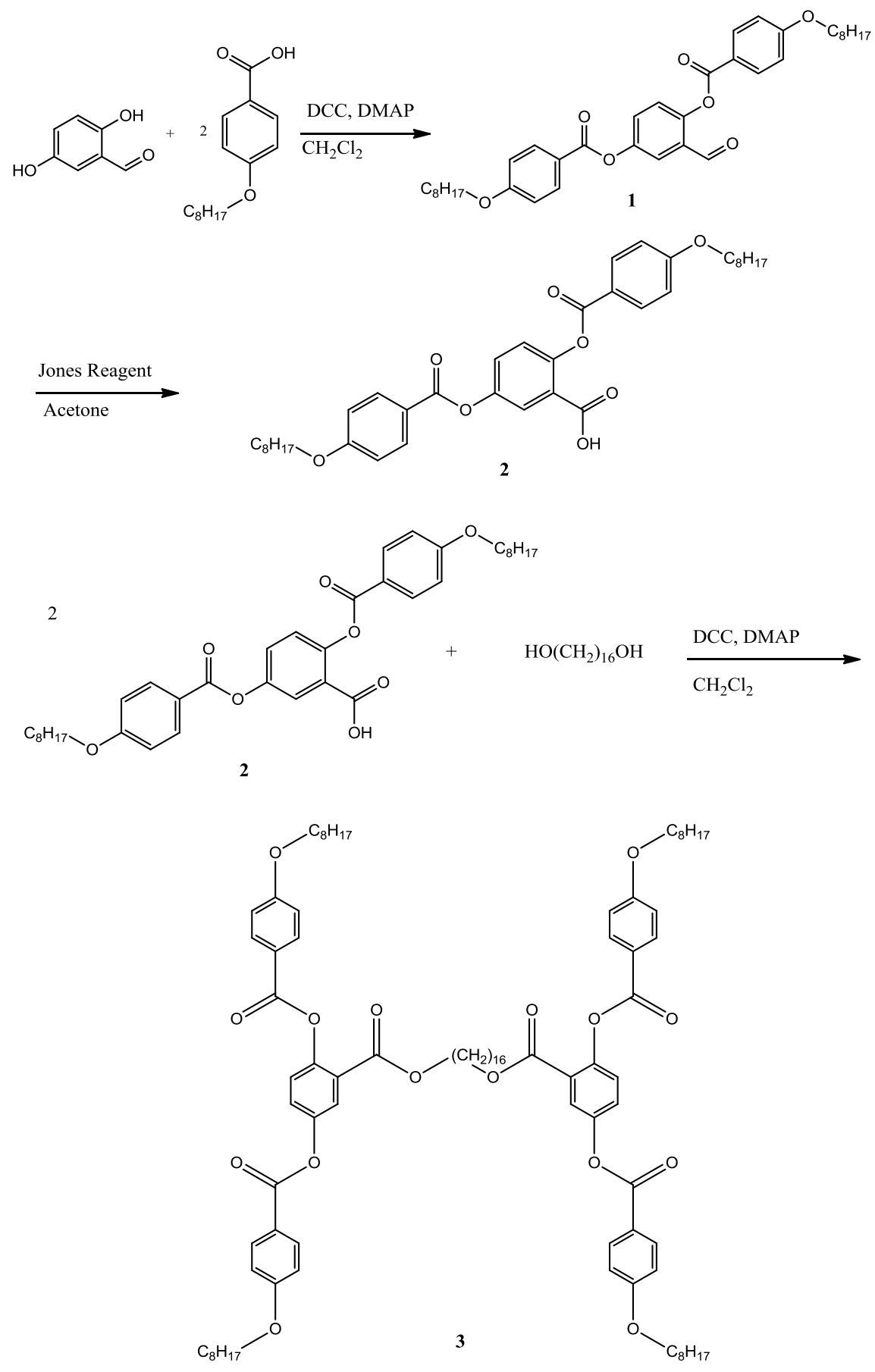


\section{Experimental}

DSC's were obtained on a TA Instruments Modulated 2920 DSC at rate of $5^{\circ} \mathrm{C} / \mathrm{min}$ under an $\mathrm{N}_{2}$ atmosphere. The ${ }^{1} \mathrm{H}$ NMR were obtained on a Bruker Avance $400 \mathrm{MHz}$ NMR using TMS as an internal standard and ${ }^{13} \mathrm{C}$ NMR were also obtained on this instrument at $100 \mathrm{MHz}$ using TMS as the internal standard.

2-formyl-4-\{[4-(octyloxy)phenyl]carbonyloxy\}phenyl 4-(octyloxy)benzoate (1). To a solution of $3.00 \mathrm{~g}(21.7 \mathrm{mmol})$ of 2,5-dihydroxybenzaldehyde and $13.57 \mathrm{~g}(54.3 \mathrm{mmol})$ of 4-octyloxybenzoic acid dissolved in $200 \mathrm{ml}$ of $\mathrm{CH}_{2} \mathrm{Cl}_{2}$ was added $11.19 \mathrm{~g}(54.3 \mathrm{mmol})$ of DCC and $0.080 \mathrm{~g}(0.64 \mathrm{mmol})$ of DMAP. This solution was stirred at room temperature overnight. The resulting mixture was vacuum filtered through Celite to remove the DCU byproduct. The solvent was removed in vacuo and the resulting solid was recrystallized from ethanol to afford the product as an off-white powder. Yield $10.585 \mathrm{~g}(81.0 \%) .{ }^{1} \mathrm{H}$ NMR $\left(\mathrm{CDCl}_{3}\right), \delta 10.24 \mathrm{~s}(1 \mathrm{H}), 8.20 \mathrm{~m}(4 \mathrm{H}), 7.81 \mathrm{~d}(1 \mathrm{H}, J=2.8$ $\mathrm{Hz}), 7.56 \mathrm{dd}(1 \mathrm{H}, J=2.8,8.8 \mathrm{~Hz}), 7.41 \mathrm{~d}(1 \mathrm{H}, J=8.8 \mathrm{~Hz}), 7.02 \mathrm{~m}(4 \mathrm{H}), 4.09 \mathrm{~m}(4 \mathrm{H})$, $1.86 \mathrm{~m}(4 \mathrm{H}), 1.51 \mathrm{~m}(4 \mathrm{H}), 1.33 \mathrm{~m}(16 \mathrm{H}), 0.92 \mathrm{t}(6 \mathrm{H}, J=6.8 \mathrm{~Hz}) .{ }^{13} \mathrm{C} \mathrm{NMR}\left(\mathrm{CDCl}_{3}\right), \delta$ : 187.5 , 164.6, 164.5, 164.1, 163.8, 150.0, 148.8, 132.6, 132.4, 129.1, 128.8, 124.7, 122.3, 120.8, 120.3, 114.6, 114.4, 68.4, 31.8, 29.3, 29.2, 29.1, 26.0, 22.7, 14.1. M.P. $150-152^{\circ} \mathrm{C}$.

2,5-bis(\{[4-(octyloxy)phenyl]carbonyloxy\})benzoic acid (2). To a solution of aldehyde 1 dissolved in $200 \mathrm{ml}$ of acetone was added $17.1 \mathrm{ml}(26.4 \mathrm{mmol})$ of $1.54 \mathrm{M}$ Jones Reagent. ${ }^{1}$ This solution was stirred overnight at room temperature. The solvent was then removed in vacuo and $500 \mathrm{ml}$ of water were added to the remaining solids. The resulting slurry was stirred for one hour and the solids were filtered off and washed copiously with water to give the product as a white powder. Yield $10.812 \mathrm{~g}(99.4 \%) .{ }^{1} \mathrm{H}$ NMR $\left(\mathrm{CDCl}_{3}\right), \delta 8.15 \mathrm{~m}(4 \mathrm{H}), 7.96 \mathrm{~d}(1 \mathrm{H}, J=2.4 \mathrm{~Hz}), 7.53 \mathrm{dd}(1 \mathrm{H}, J=2.8,8.8 \mathrm{~Hz})$, $7.32 \mathrm{~d}(1 \mathrm{H}, J=8.8 \mathrm{~Hz}), 6.99 \mathrm{~m}(4 \mathrm{H}), 4.08 \mathrm{~m}(4 \mathrm{H}), 1.85 \mathrm{~m}(4 \mathrm{H}), 1.51 \mathrm{~m}(4 \mathrm{H}), 1.33 \mathrm{~m}$ $(16 \mathrm{H}), 0.92 \mathrm{t}(6 \mathrm{H}, J=6.4 \mathrm{~Hz}) \cdot{ }^{13} \mathrm{C} \mathrm{NMR}\left(\mathrm{CDCl}_{3}\right), \delta: 164.9,164.5,163.8,163.6,148.7$, $148.3,132.5,132.4,128.0,125.5,125.2$, 123.4, 121.3, 120.9, 114.4, 114.3, 68.4, 68.3, $31.8,29.3,29.2,29.1,26.0,22.7,14.1$. M.P $167-169^{\circ} \mathrm{C}$. 


\section{Exemplary method for the synthesis of $\mathbf{H}$-shaped adducts from carboxylic acid 2:}

16-\{[2,5-bis(\{[4-(octyloxy)phenyl]carbonyloxy\})phenyl]carbonyloxy\}hexadecyl 2,5bis(\{[4-(octyloxy) phenyl]carbonyloxy\})benzoate (3). To a solution of $0.500 \mathrm{~g}(0.81$ mmol) of acid 2 and $0.101 \mathrm{~g}(0.39 \mathrm{mmol})$ of 1.16-hexadecanediol that were dissolved in $25 \mathrm{ml} \mathrm{CH} \mathrm{Cl}_{2}$ was added $0.167 \mathrm{~g}(0.81 \mathrm{mmol})$ of DCC and $0.010 \mathrm{~g}(0.08 \mathrm{mmol})$ of DMAP. This solution was stirred at room temperature overnight. The resulting mixture was filtered through Celite to remove the DCU byproduct. The solvent was removed in vасио and the resulting solid was recrystallized from 3-methyl-1-butanol to afford a white powder. Yield 0.329g (65.5\%). IR $v_{\max }(\mathrm{Neat}) / \mathrm{cm}^{-1} 2921,2852,1731,1606$, 1510, 1248, 1160, 1063, 760. ${ }^{1} \mathrm{H}$ NMR $\left(\mathrm{CDCl}_{3}\right), \delta 8.18 \mathrm{~m}(8 \mathrm{H}), 7.92 \mathrm{~d}(2 \mathrm{H}, J=2.8 \mathrm{~Hz})$, $7.48 \mathrm{dd}(2 \mathrm{H}, J=2.8,8.8 \mathrm{~Hz}), 7.28 \mathrm{~d}(2 \mathrm{H}, J=8.4 \mathrm{~Hz}), 7.00 \mathrm{~m}(8 \mathrm{H}), 4.17 \mathrm{t}(4 \mathrm{H}, J=7.2$ $\mathrm{Hz}), 4.07 \mathrm{~m}(8 \mathrm{H}), 1.85 \mathrm{~m}(8 \mathrm{H}), 1.50 \mathrm{~m}(12 \mathrm{H}), 1.33 \mathrm{~m}(32 \mathrm{H}), 1.25 \mathrm{~m}(24 \mathrm{H}), 0.92 \mathrm{~m}$ $(12 \mathrm{H}) .{ }^{13} \mathrm{C} \mathrm{NMR}\left(\mathrm{CDCl}_{3}\right), \delta: 164.9,164.6,164.2,163.8,163.6,148.3,148.1,132.5$, $132.4,127.0,125.0,121.5,121.0,114.4,114.3,68.4,68.3,65.7,31.8,29.7,29.6,29.5$, $29.3,29.2,29.1,28.4,26.0,25.9,22.7,14.1$.

DSC Heating Cycle- Cr 101.3 N 105.3 Iso Cooling Cycle- Iso 103.9 N 31.6 Cr 